\title{
BMJ Open Comparison of common interventions for the treatment of infantile colic: a systematic review of reviews and guidelines
}

Julie Ellwood, ${ }^{1}$ Jerry Draper-Rodi, ${ }^{1}$ Dawn Carnes (D) ${ }^{1,2}$

To cite: Ellwood J, DraperRodi J, Carnes D. Comparison of common interventions for the treatment of infantile colic: a systematic review of reviews and guidelines. BMJ Open 2020;10:e035405. doi:10.1136/ bmjopen-2019-035405

- Prepublication history and additional material for this paper are available online. To view these files, please visit the journal online (http://dx.doi. org/10.1136/bmjopen-2019035405).

Received 04 November 2019 Revised 31 January 2020 Accepted 03 February 2020

Check for updates

(C) Author(s) (or their employer(s)) 2020. Re-use permitted under CC BY-NC. No commercial re-use. See rights and permissions. Published by BMJ.

${ }^{1}$ Research Department, University College of Osteopathy, London, UK

${ }^{2}$ Faculty of Health, University of Applied Sciences Western Switzerland, Fribourg,

Switzerland

Correspondence to

Dr Dawn Carnes;

dawn.carnes@uco.ac.uk

\section{ABSTRACT}

Objective To conduct a systematic review of systematic reviews and national guidelines to assess the effectiveness of four treatment approaches (manual therapy, probiotics, proton pump inhibitors and simethicone) on colic symptoms including infant crying time, sleep distress and adverse events.

Methods We searched PubMed, Embase, Cochrane and Mantis for studies published between 2009 and 2019. Inclusion criteria were systematic reviews and guidelines that used evidence and expert panel opinion. Three reviewers independently selected articles by title, abstract and full paper review. Data were extracted by one reviewe and checked by a second. Selected studies were assessed for quality using modified standardised checklists by two authors. Meta-analysed data for our outcomes of interest were extracted and narrative conclusions were assessed. Results Thirty-two studies were selected. High-level evidence showed that probiotics were most effective for reducing crying time in breastfed infants (range -25 min to -65 min over 24 hours). Manual therapies had moderate to low-quality evidence showing reduced crying time (range -33 min to -76 min per 24 hours). Simethicone had moderate to low evidence showing no benefit or negative effect. One meta-analysis did not support the use of proton pump inhibitors for reducing crying time and fussing. Three national guidelines unanimously recommended the use of education, parental reassurance, advice and guidance and clinical evaluation of mother and baby. Consensus on other advice and treatments did not exist.

Conclusions The strongest evidence for the treatment of colic was probiotics for breastfed infants, followed by weaker but favourable evidence for manual therapy indicated by crying time. Both forms of treatment carried a low risk of serious adverse events. The guidance reviewed did not reflect these findings.

PROSPERO registration number CRD42019139074.

\section{INTRODUCTION}

Infantile colic, which is defined as excessive crying in the first few months of life, is a common but poorly understood and often frustrating problem for parents and carers. Infantile colic affects somewhere between $3 \%$ and $40 \%$ of infants worldwide, depending on
Strengths and limitations of this study

- This study compares meta-data from different treatments for infantile colic on common outcomes.

- Guidance and evidence are compared.

- Distinguishing superiority of treatments is difficult with multiple subpopulations and outcomes.

- Where aetiology of a condition is uncertain, rationale for treatments are difficult to justify.

- Effectiveness studies and efficacy studies are needed in this field.

geography and definitions used. ${ }^{1}$ It is estimated that around one in six families $(17 \%)$ with children consult a health professional about symptoms associated with infantile colic, and these include excessive crying, fussing and distress. ${ }^{2}$

Infants cry for various reasons to express discomfort caused by conditions ranging from benign disorders to life-threatening illness. A meta-analysis published in 2017, which included 28 diary studies covering 8690 infants, reported a mean daily fuss and cry duration of $117 \mathrm{~min}$ to $133 \mathrm{~min}$ in the first 6 weeks of life, followed by a decline in crying time to a mean of 68 min per day by 10 to 12 weeks of age. ${ }^{3}$ It is suggested that less than $5 \%$ of distressed infants have identifiable medical explanations for their crying. ${ }^{4}$

There is confusion around the terminology and diagnosis of infantile colic with other diagnostic terms such as silent reflux, functional gastrointestinal disorder and sometimes infantile headache to explain the symptoms of colic. A systematic review of definitions and outcome measures in trials of infantile colic reported the current variability in defining infantile colic, which parallels the nonuniformity of measuring the condition. ${ }^{5}$ Most definitions are based on Wessel's criteria, also known as the 'rule of threes', which defines colic as paroxysms of irritability, fussing or 
crying lasting $\geq 3$ hours per day on $\geq 3$ days per week for $>3$ weeks $^{6}$ in an otherwise healthy baby aged 2 weeks to 4 months. However, these criteria have been found to be out of date and impractical to use. ${ }^{7}$ The most recent diagnostic criteria, formulated by the Rome IV committee, are recurrent and prolonged periods of crying without an obvious cause or evidence of failure to thrive or illness in infants younger than 5 months. ${ }^{8}$

The natural history of infantile colic is favourable with symptoms gradually disappearing by the time the infant is 4 months old. ${ }^{9}$ However, the impact of excessive infant crying on healthcare services is the most common reason for paediatric consultations and hospital emergency department visits in the first weeks of life. ${ }^{10}$ The consequences of having an excessively crying infant in the family are harmful to relationships and health. ${ }^{11}$ Excessive infant crying is associated with maternal issues such as depression, anxiety and loss of parenting confidence. ${ }^{12} 13$ It is also a common cause of early breastfeeding cessation $^{14}$ and has been associated with severe infant injury or death as a result of abuse. ${ }^{15}$

Recommended management strategies usually centre around parental support and reassurance that the infant is otherwise healthy. However, parents are often in a state of crisis and feel that they want to take action. A number of treatment options exist, which include pharmacological treatments (eg, dicyclomine hydrochloride, cimetropium bromide, simethicone and proton pump inhibitors), probiotics, complementary therapies (including herbal agents and sucrose), manual therapies (for example chiropractic, osteopathy and physiotherapy), dietary interventions and parental behavioural interventions.

Reviews to date have assessed the effectiveness of manipulative therapies, ${ }^{16}$ probiotics, ${ }^{17}$ dietary modification, ${ }^{18}$ complementary and alternative therapies (herbal formulations, sucrose or glucose $)^{19}$ and pain-relieving agents. ${ }^{19}$ However, there is limited research which compares these treatments to inform the management of infants experiencing colic and parental decision-making. ${ }^{9}$

\section{AIM}

The aim of this study was to review and compare the effectiveness of manual therapy to three of the most common interventions (probiotics, simethicone and proton pump inhibitors) on colic symptoms in infants, including crying time, sleep and infant distress and adverse events.

\section{METHODS}

We conducted a pragmatic narrative systematic review of systematic reviews (SRs) and clinical guidelines for the most common treatments of infantile colic. We employed a review approach using existing analyses of information whether it was based on compiled narrative analyses, meta-analysis or guideline consensus review. A network meta-analyses for comparing outcomes across treatments was not considered as we were aware from the pre-scoping stage of this review that the studies were too heterogeneous in terms of quality between treatment type. The review protocol was registered on the International prospective register of systematic reviews, and this report follows the guidance in the PRISMA statement ${ }^{20}$ for reporting reviews.

\section{Eligibility criteria}

Our population of interest were infants (under 6 months old) with colic as defined by either Wessel's or the ROME III or IV criteria. ${ }^{67}$ We were not considering infants with diagnosed gastro-oesophageal reflux disease (GORD), as this is considered a pathological condition and differs from colic in that the infants are generally not thriving.

Only children who were otherwise healthy and thriving were included in this study, that is, no other dominant or serious comorbidity requiring medical care in a nonprimary care setting.

We considered four treatments for infantile colic: manual therapy, simethicone, proton pump inhibitors and probiotics as these were considered most widely recognised and of interest to the funder. We included the use of proton pump inhibitors because, while it is not recommended for use in infants with colic, it is increasingly being used with these infants to 'rule out' reflux and or GORD, as symptoms of colic are thought to be secondary to GORD. ${ }^{21}$ Dicyclomine treatment for infantile colic (anti-spasmodic drug) was excluded in this study as it is not recommended for infants under 6 months due to contraindications, mainly respiratory symptoms varying in severity and consequence. ${ }^{22}$

We defined manual therapy as any predominantly (more than $75 \%$ ) touch-based therapy administered by a trained and registered manual therapist, such as a chiropractor, osteopath, osteopathic physician, physical therapist or physiotherapist.

The outcomes of interest were crying time, sleep and parental distress, and in addition, where data existed, adverse events data for each treatment were reviewed.

We limited the type of literature we reviewed to systematic reviews of effectiveness and national clinical guidelines.

We included reviews that reported a systematic review methodology and which had more than one researcher indicated in the review process. Narrative literature reviews and editorials were not included.

We included clinical guidelines where clear methodological procedures for development were reported and included systematically designed evidence reviews and expert panel consensus. The guidance had to be intended for broad use at a national level rather than intended as guidance for a single clinic or hospital or a specific setting. We excluded guidance targeted at parents.

We limited the literature to that published in the last decade between 2009 and 2019 and written in English. 


\section{Information sources}

For systematic reviews, we searched PubMed, MANTIS, EMBASE, Cochrane and for guidelines we searched those published in English by national organisations. The searches were conducted in June 2019.

\section{Search}

Key search terms used were 'systematic reviews', infant*, colic, 'manual therapy', 'manipulative medicine', simethicone, 'proton pump inhibitors', 'PPIs', probiotics, 'probiotic agents' (see online supplementary appendix 1).

We searched the central clearing guideline database and known national guideline centres for guidelines on the treatment, management and care of babies with unsettled or distressed behaviour, including infantile colic.

\section{Study selection}

Results from searches on each database were downloaded into a Reference Management Software, EndNote (V.X4.0.2), and duplicates were removed; titles and abstracts were screened by two independent researchers. Inclusion/exclusion decisions were made by all three authors. Citation tracking was used to triangulate our searches and check for missing reviews and guidance, as well as to identify other articles that may have not been indexed in PubMed. Full-text papers were obtained for those that met the inclusion criteria and for those where it was unclear whether or not the abstract and title met the inclusion criteria. If a more recent or updated versions of reviews or guidelines were found, the more recent ones replaced those initially found.

\section{Quality appraisal}

We appraised the quality of the systematic reviews using a modified version of the AMSTAR 2 critical appraisal tool. ${ }^{23}$ Of the 15 quality categories assessed, 8 were selected by the authors for the final calculation of quality and we allocated a score of 1 for Yes, 0 for No and 0.5 for Partial Yes. The scale ranged from 0 to 8 (Highest quality). Each study was appraised by two independent reviewers and a third reviewer was used if mitigation was required (see online supplementary appendix 2).

We reported on the quality of the guidelines using a modified version of the AGREE II framework. ${ }^{24}$ The AGREE II checklist has 23 items evaluating six domains. Where more than $75 \%$ of the 23 items $(>17 / 23)$ were met, we rated these as high-quality guidance. In guidance, where there was insufficient information to record a verdict, we left these domains blank. Guidelines of 16 or less domains did not receive an evaluation of high quality. Each guideline was appraised by one reviewer (see online supplementary appendix 3).

\section{Data extraction and items}

We summarised studies by type of intervention, number of studies included, number of participants and outcomes of interest and measure used (table 1). We extracted meta-analysed data on hours of crying time and sleeping time between intervention and control groups and other active interventions. For parent distress and confidence, we proposed to compare effect sizes and/or change scores on similar outcomes. In the absence of metaanalysis, change scores or effect size data, we conducted a narrative synthesis of outcomes.

We also extracted adverse event incident data and compared risk ratios between treatments and controls where possible. One researcher extracted characteristics and data from the selected articles, and this was checked by a second researcher. A third reviewer's opinion was sought in cases of disagreement in the extraction process.

\section{Level of evidence}

We used reported levels of evidence as published in the reviews and guidance and analysed these to indicate overall level of publication consensus on effectiveness and safety. The strength of the overall evidence was determined by the reviews and guidance evaluated as Favourable-significant benefit to treatment compared with control; Not favourable-no significant benefit to treatment compared with control or no difference between treatment and controls; Unfavourable-results for treatment worse than control; Inconclusive-unable to draw conclusions from results.

\section{Patient and public involvement}

No patient involvement.

\section{RESULTS}

\section{Study selection}

We found 201 studies for screening against title and abstract of which 126 were excluded and 75 were selected for full paper review. Of these, a further 43 were excluded and 32 references were finally included in this systematic review. See figure 1 flow chart illustrating the process and reasons for exclusion.

Eleven studies investigated the effectiveness of manual therapy for treating infantile colic, 12 for probiotics, 1 for proton pump inhibitors, 4 for simethicone and 4 papers which included a combination of the interventions of interest in this review.

The characteristics of the final selection of studies are shown in tables 1-5 ordered by interventions: manual therapy, simethicone, probiotics, proton pump inhibitors and mixed interventions.

The control arms varied for the studies included in the systematic reviews: for example, in the probiotic, proton pump inhibitors and simethicone studies, the controls were mainly placebos or usual feeding method (mainly breast feeding); and in the manual therapy studies, the controls were either no treatment, usual care, dimethicone and in one craniosacral decompression.

\section{Outcome measures}

Crying time was the most reported outcome (26/32 studies). In three studies, crying episodes (as opposed 


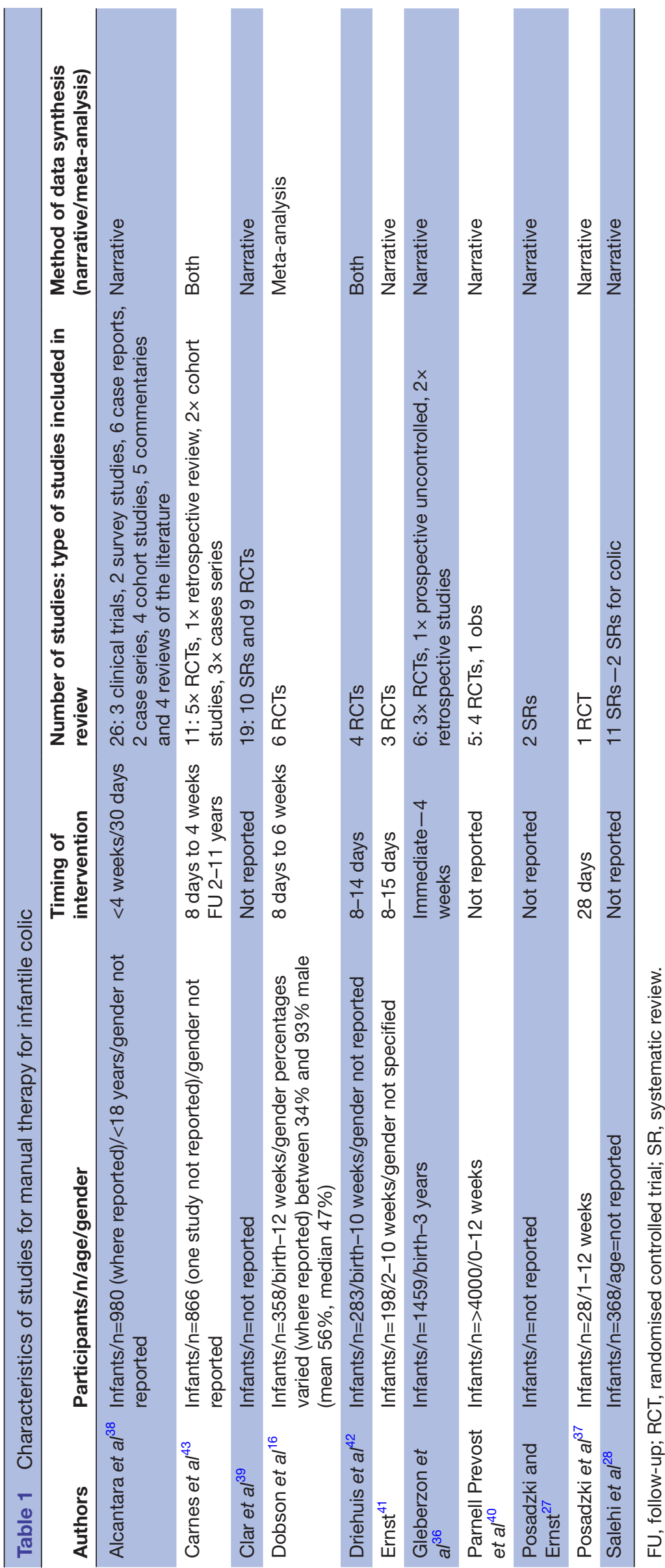

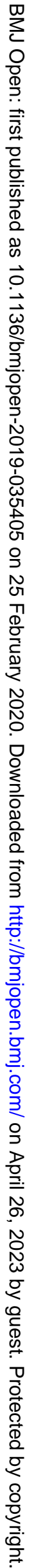




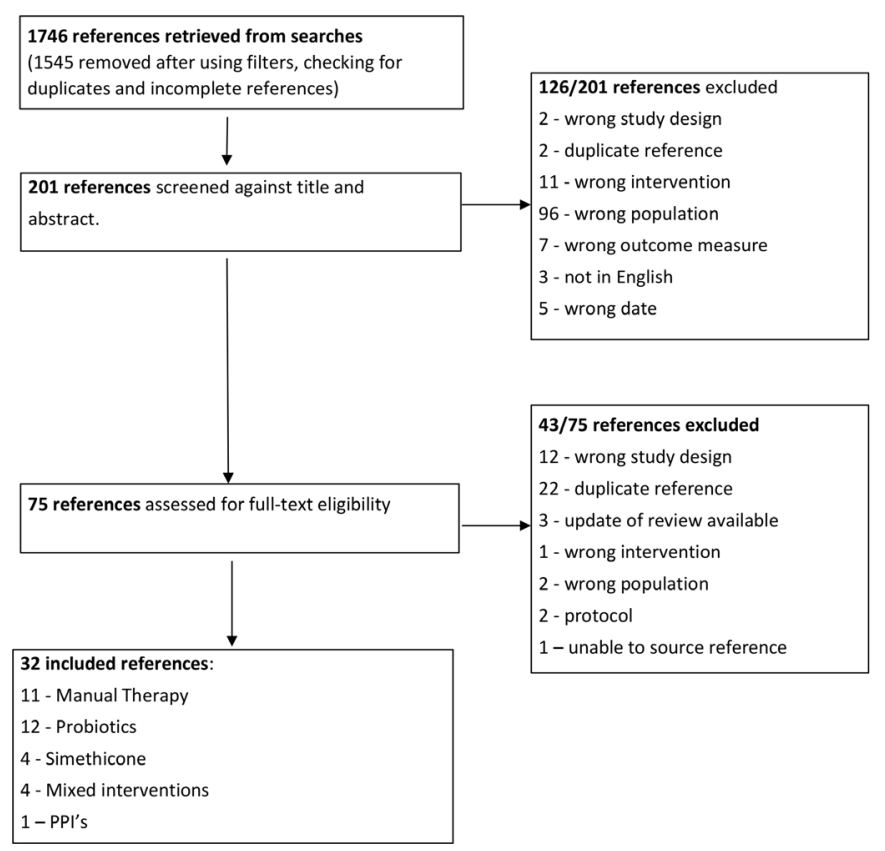

Figure 1 Flowchart of search process for the review. PPI, proton pump inhibitor.

to crying duration) were recorded as the outcome measure. ${ }^{182526}$ Three studies did not report outcome data. $^{27-29}$

Fourteen of the 26 papers that reported crying time conducted a meta-analysis. One study ${ }^{30}$ reported outcomes for all three interventions and another ${ }^{31}$ reported metaanalysed data for probiotic use and narrative analysis for simethicone. There were 10 meta-analysed results for probiotics, 2 for simethicone and 4 for manual therapy. The data indicated that for breastfed infants, probiotics significantly decreased daily crying time (range -25 min to -65 min). The level of evidence for these findings was reported as high (as indicated by the systematic reviewer authors' appraisal of quality and/or risk of bias) with seven studies reporting high quality, one moderate and two low quality. There were four systematic reviews investigating effectiveness of manual therapy for crying, three showed favourable effects (from -33 min to -76 hours of crying time reduction in 24 hours) and one review was inconclusive. The quality of these randomised controlled trials (RCTs) ranged from moderate to low by the authors of the SRs.

The findings from two studies investigating the effects of simethicone were inconclusive or not favourable and were graded as moderate/low quality. Table 6 shows the meta-analysed data for crying time.

There were three studies that reported the number of crying episodes; one was a meta-analysis on the effectiveness of probiotics ${ }^{25}$ and the other two were narrative analyses, one for probiotics ${ }^{26}$ and one where simethicone was used as the control arm compared with partially hydrolysed formula. ${ }^{18}$ The results from these three studies did not support the use of probiotics or simethicone for the treatment of infantile colic and the quality of the studies were reported as low in all studies (see table 7).
Narrative analysis

Crying time

Thirteen of the 26 studies reporting on crying times conducted a narrative review. Two of the studies ${ }^{232}$ reported on the effectiveness of both probiotics and manual therapy for treating infantile colic. Of the four studies that reported on probiotics, one reported a favourable outcome when compared with simethicone. ${ }^{33}$ The other studies did not support the use of probiotics and were of low-grade quality.

Two reviews narratively reported on the effects on crying time using simethicone; the findings did not support its use. $^{3134}$ The quality of the studies in these reviews were graded as low by the review authors.

One review reported on crying time, crying episodes, crying time post feeding and parent perception of change in fussing time between infants taking proton pump inhibitors and a placebo. They found no significant differences between groups on any outcome and concluded in the light of associated adverse events unfavourable evidence for the use of proton pump inhibitors. ${ }^{35}$

Eight studies reported on the effectiveness of manual therapy for infantile colic. Two studies reported a favourable outcome, ${ }^{3637}$ four were inconclusive, ${ }^{32} 38-40$ one study showed no beneficial effects over the control $\operatorname{arm}^{41}$ and one study reported an unfavourable outcome. ${ }^{2}$ Most of the reviews for manual therapy graded the RCT studies as low quality.

The findings are summarised in table 8.

Three further narrative studies, two for manual therapy ${ }^{2728}$ and one for simethicone, ${ }^{29}$ did not report details on how the effectiveness of interventions was measured. The results of these studies were reported as unfavourable or inconclusive and the quality of the studies were low.

\section{Adverse events}

When reported, there were no serious adverse events reported in the RCTs for either manual therapy, simethicone or probiotics. In one $\mathrm{SR},{ }^{42}$ four serious adverse events were documented in case studies of manual therapy, including a death, temporary paralysis and a rib fracture, but because these were poorly described and missed underlying pathology could not be ruled out, the overall risk where reported was low. Risks of developing infections with probiotics were reported as extremely low. ${ }^{33}$ The review on PPIs showed both arms had adverse events, one RCT showed a significant difference between lansoprazole and the placebo for totality of serious adverse effects, mainly lower respiratory tract infections $(10 / 81$ vs $2 / 81$, risk ratio $5,95 \%$ CI 1.3 to 20 , number needed to harm $11,95 \%$ CI 6 to 49$)^{21}$ (see online supplementary appendix 4).

\section{Guidelines for the treatment, care and management of infants with colic}

We found three national clinical guidelines about the treatment and management of 'colicky' infants.

Table 9 summarises the recommendations they made. The quality rating for the UK guideline development 
Table 2 Characteristics of studies for probiotics for infantile colic

\begin{tabular}{|c|c|c|c|c|}
\hline Authors & Participants/n/age/gender & $\begin{array}{l}\text { Treatment and timing of } \\
\text { intervention }\end{array}$ & $\begin{array}{l}\text { Number of studies: } \\
\text { type of studies } \\
\text { included in review }\end{array}$ & $\begin{array}{l}\text { Method of data } \\
\text { synthesis (narrative/ } \\
\text { meta-analysis) }\end{array}$ \\
\hline Anabrees et $a l^{52}$ & $\begin{array}{l}\text { Breastfed or partly breastfed } \\
\text { infants } / n=209 /<4 \text { months/gender } \\
\text { not reported }\end{array}$ & $\begin{array}{l}\text { L. reuteri (strains- } \\
\text { American Type Culture } \\
\text { Collection Strain } 55730 \\
\text { and DSM 17938) } \\
21 \text { days and } 28 \text { days }\end{array}$ & $\begin{array}{l}\text { 3: } 1 \times \text { Open prospective } \\
\text { randomised study, } 2 \times \\
\text { double-blind } \mathrm{RCTs}\end{array}$ & Meta-analysis \\
\hline Cruchet et $\left.a\right|^{33}$ & $\begin{array}{l}\text { Infants } / \mathrm{n}=\text { not reported/age not } \\
\text { reported/gender not reported }\end{array}$ & $\begin{array}{l}\text { L. reuteri, B. lactis and Str. } \\
\text { thermophiles } \\
\text { Not reported }\end{array}$ & 9: $1 \times \mathrm{SR}, 8 \times \mathrm{RCTs}$ & Narrative \\
\hline Ong et $a l^{17}$ & Infants $/ \mathrm{n}=1886 /<1$ month & $\begin{array}{l}\text { L. reuteri DSM, multistrain } \\
\text { probiotics, } L \text {. rhamnosus, } \\
\text { L. paracasei and } B \text {. } \\
\text { animalis } \\
4 / 52 \text { before delivery to } 6 \\
\text { months }\end{array}$ & 6 RCTs & Meta-analysis \\
\hline Schreck Bird et $a /^{55}$ & Infants $/ \mathrm{n}=444 / 31-52$ days & $\begin{array}{l}\text { L. reuteri DSM } 17938\left(10^{8}\right. \\
\text { CFU) } \\
21 \text { and } 28 \text { days }\end{array}$ & $5 \mathrm{RCTs}$ & Narrative \\
\hline
\end{tabular}

CFU, colony-forming unit; RCT, randomised controlled trial; SR, systematic review.

process and reporting met $18 / 23$ criteria, the USA and the Irish guidance 11/23.

\section{DISCUSSION}

\section{Summary of findings and context}

We found 32 relevant systematic reviews and three examples of guidance. Many of the RCTs were repeated within the reviews and this is reflected by fairly consistent results but differing interpretations. Overall, the meta-analysed results showed that both probiotics in breastfed infants and manual therapy can reduce crying time. The daily reduction in crying is between 33 and 76 min with manual therapy and between $25 \mathrm{~min}$ and $65 \mathrm{~min}$ with probiotics in breastfed infants. The quality and strength of evidence was higher for probiotics than manual therapy. The evidence for probiotics centred on breastfed infants rather than formula-fed infants and there were a number of different types of strains of probiotics. The manual therapy evidence was based on low to moderate quality RCTs and therefore larger blinded RCTs were recommended. In addition, crying time was reported as the primary outcome in most studies which was used as a proxy indicator of colic resolution or improvement.

There were no serious adverse events reported for either probiotics or manual therapy, indicating that both represent a low risk to infants, although we cannot conclude they are without any risk. ${ }^{2742}$ Two reviews ${ }^{1643}$ analysed the risks of adverse events with manual therapy, one showed $88 \%$ less risk of an adverse event in the manual therapy groups than in the control groups ${ }^{43}$ and the other showed one in six parents reported non-serious adverse events. ${ }^{16}$ Another study ${ }^{42}$ reported data from non-RCTs which included four case studies reporting serious incidents of harm but there was some doubt over causality as a result 
Table 3 Characteristics of studies for simethicone for infantile colic

\begin{tabular}{|c|c|c|c|c|}
\hline Authors & Participants/n/age/gender & Timing of intervention & $\begin{array}{l}\text { Number and } \\
\text { type of studies } \\
\text { included in } \\
\text { review }\end{array}$ & $\begin{array}{l}\text { Method of } \\
\text { data synthesis } \\
\text { (narrative/meta- } \\
\text { analysis) }\end{array}$ \\
\hline Gordon et al ${ }^{18}$ & $\begin{array}{l}\text { Infants } / \mathrm{n}=1121 / 2-16 \text { weeks/balanced } \\
\text { numbers of boys and girls }\end{array}$ & 4-21 days & $1 \mathrm{RCT}$ & Narrative \\
\hline $\begin{array}{l}\text { Salvatore et } \\
\mathrm{al}^{29}\end{array}$ & 1 consensus review, 1 review, 1 SR & NA & NA & Narrative \\
\hline $\mathrm{Xu}$ et $a l^{58}$ & Infants $/ n=423 / 3-6$ months & $\begin{array}{l}\text { L. reuteri. } 21 \text { and } 28 \\
\text { days }\end{array}$ & 6 RCTs & Meta-analysis \\
\hline
\end{tabular}

NA, not available; RCT, randomised controlled trial; SR, systematic review.

of the treatments given. The risk with probiotic was very low. ${ }^{17}$

The data for simethicone and proton pump inhibitors were unfavourable with five reviews concluding either no difference or worsening of symptoms with the use of simethicone. One review concluded no significant differences in crying time or episodes with proton pump inhibitors compared with a placebo, but there was evidence of serious adverse events with the proton pump inhibitor group (one RCT) ${ }^{42}$ Other older reviews have concluded the same. ${ }^{22}$

We found few systematic reviews assessing the effectiveness of PPIs for colic despite their increasing use in this population. ${ }^{2144}$ This is because most studies investigating the use of PPIs were for GORD with symptoms of colic. We are aware, however, of the practice of using PPIs to diagnose GORD by treatment. ${ }^{44}$ PPIs are designed to suppress acid but have consistently been shown to be ineffective for irritability and fussing in infants with GORD, and they are associated with an increased risk of adverse effects such as infections, allergies and hospital admissions. ${ }^{9} 21354546$ There is evidence from Australia to show that PPIs are being over-prescribed for infants with physiological reflux and symptoms of colic who may or do not have GORD. The reasons are complex, but the authors suggest they centre around inconsistent diagnostic criteria and diagnostic labelling and 'defensive' medicine practice to substantiate the diagnosis with the expectation to medicate. ${ }^{47}$ None of the guidance reviewed recommended the use of PPIs for the treatment of colic.

We found three nationally representative guidance, and the only other guidance we found was directed at parents with unclear sources of evidence and guidance justification. Clinical evaluation, information, advice, support and reassurance were the only guidance that was agreed in all four guidelines. Three of the four guidelines recommended to continue to breast feed and use physical contact and not to recommend simethicone and manual therapy, despite the difference in current evidence between them, that is, favourable moderate to low quality for manual therapy and unfavourable low quality for simethicone. Despite the stronger evidence for probiotics in breastfed infants, this was only recommended as a treatment to consider in the USA and Irish guidance. The Canadian Paediatric Association issued a position statement in 2012 which was updated in 2019 stating: "While there may be a role for probiotics in treating infantile colic, there is insufficient evidence to recommend for or against using probiotics to manage this condition". ${ }^{48}$

Only the USA guidance specifically states not to use proton pump inhibitors for the treatment of colic. We do not know the level of proton pump inhibitors use in

Table 4 Characteristics of studies for proton pump inhibitors for infantile colic

\begin{tabular}{llll} 
Authors & Participants/n/age/gender & $\begin{array}{l}\text { Timing of } \\
\text { intervention }\end{array}$ & $\begin{array}{l}\text { Number and type of studies } \\
\text { included in review }\end{array}$ \\
\hline Gieruszczak-Białek et $\left.a\right|^{35}$ & Infants/n=404/<12 months & $2-4$ weeks & 5 RCTs \\
\hline
\end{tabular}

$\mathrm{RCT}$, randomised controlled trial. 


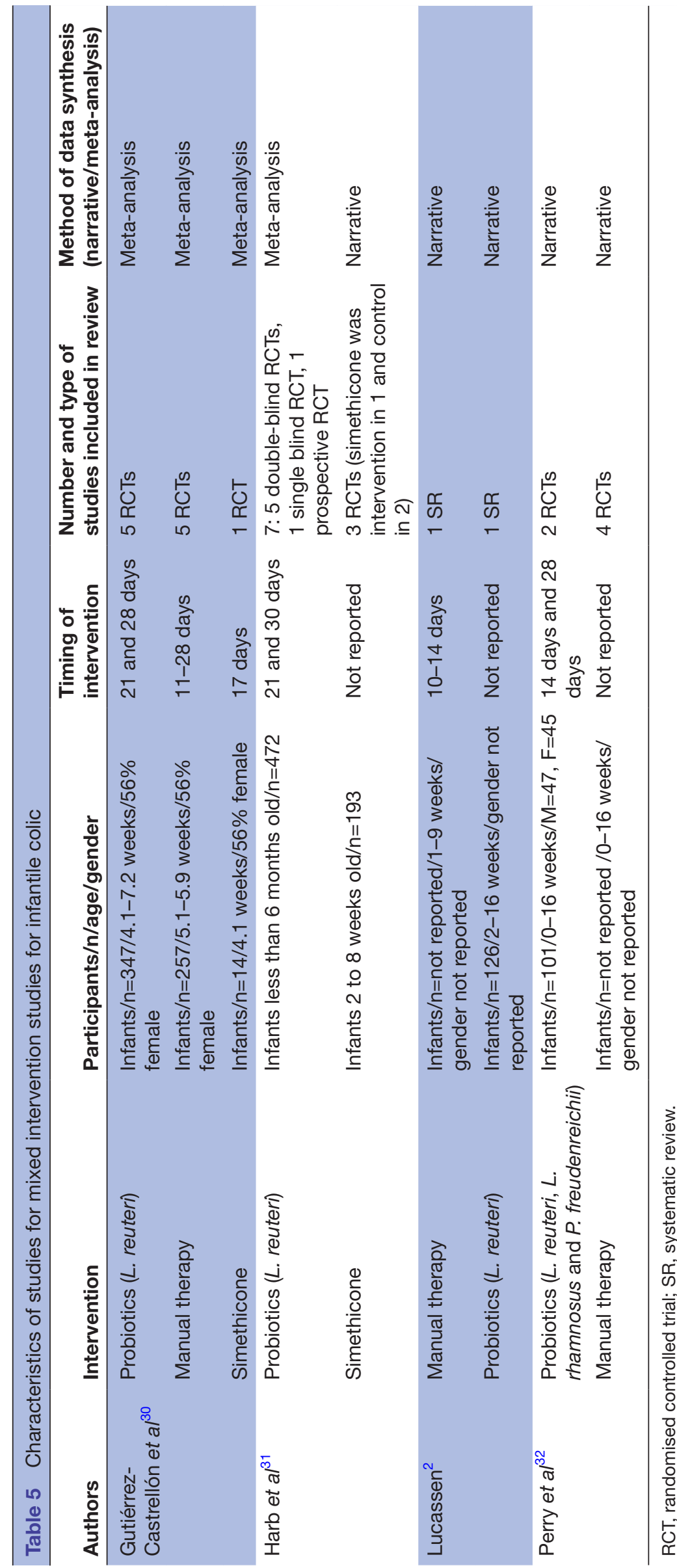

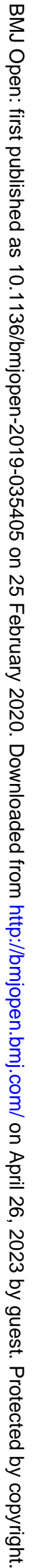


Table 6 Summary of meta-analyses of treatments for infant colic measured by crying time

\begin{tabular}{|c|c|c|c|c|c|}
\hline Author & Time point & 24 hours crying time & Effect & Level of evidence & AMSTAR \\
\hline \multicolumn{6}{|l|}{ Probiotics* } \\
\hline Ong et $a l^{17}$ & 30-90 days & $\begin{array}{l}-32.57 \mathrm{~min} \\
(95 \% \mathrm{Cl}-55.6 \text { to }-9.54)\end{array}$ & Favourable & Low & 7 \\
\hline $\begin{array}{l}\text { Dryl and } \\
\text { Szajewska }\end{array}$ & $\begin{array}{l}21 \text { days and } 28 \\
\text { days }\end{array}$ & $\begin{array}{l}-49 \min \\
(95 \% \mathrm{Cl}-66 \text { to }-33) \text { for } L \text {. reuteri only }\end{array}$ & Favourable & High & 5.5 \\
\hline Sung et $\left.a\right|^{57}$ & 21 days & $-25.4 \min (95 \% \mathrm{Cl}-47.3$ to -3.5$)$ & Favourable & High & 6.5 \\
\hline $\begin{array}{l}\text { Schreck Bird et } \\
\left.a\right|^{55}\end{array}$ & $\begin{array}{l}21 \text { days } \\
28 \text { days }\end{array}$ & $\begin{array}{l}2.3 \text { times more likely to have } a \geq 50 \% \\
\text { reduction }(p=0.01)\end{array}$ & Favourable & High & 6 \\
\hline Harb et $a l^{31}$ & 21 and 30 days & $\begin{array}{l}-55.8 \mathrm{~min} \\
(95 \% \mathrm{Cl}-64.4 \text { to }-47.3)\end{array}$ & Favourable & High & 8 \\
\hline $\begin{array}{l}\text { Urbańska and } \\
\text { Szajewska }\end{array}$ & $\begin{array}{l}21 \text { days } \\
1 \text { month }\end{array}$ & $\begin{array}{l}-43 \mathrm{~min} / \text { day } \\
(95 \% \mathrm{Cl}-68 \text { to }-19)\end{array}$ & Favourable & High & 4.5 \\
\hline Sung et $a l^{56}$ & 21 days & $\begin{array}{l}-65 \min \\
(95 \% \mathrm{Cl}-86 \text { to }-44)\end{array}$ & Inconclusive & Low & 8 \\
\hline Anabrees et $a l^{52}$ & 21 and 28 days & $\begin{array}{l}-56.03 \min (95 \% \mathrm{Cl}-59.92 \text { to }-52.15), \mathrm{RR} \\
\text { of } 0.06(95 \% \mathrm{Cl} 0.01 \text { to } 0.25) \mathrm{NNT} 2\end{array}$ & Favourable & Moderate & 8 \\
\hline \multicolumn{6}{|l|}{ Simethicone } \\
\hline $\begin{array}{l}\text { Gutiérrez- } \\
\text { Castrellón et al }\end{array}$ & $7-28$ days & $\begin{array}{l}\text { WMD }-30.0 \text { min }(95 \% \mathrm{Cl}-20.8 \text { to } \\
-39.0 \text { min), } p=0.001 \text { for drugs including } \\
\text { simethicone }\end{array}$ & Inconclusive & Moderate & 7 \\
\hline Dobson et $a l^{16}$ & 8 days to 4 weeks & $\begin{array}{l}-1.2 \text { hours } \\
(95 \% \mathrm{Cl}-1.89 \text { to } 0.51)\end{array}$ & Favourable & Low & 8 \\
\hline Driehuis et $a l^{42}$ & $8-10$ days & $\begin{array}{l}-0.33 \text { hours per day }(95 \% \mathrm{Cl}-0.012 \text { to } \\
0.59)\end{array}$ & Favourable & Low & 8 \\
\hline
\end{tabular}

${ }^{*}$ Predominantly breastfed infants.

NNT, number needed to treat; RR, risk ratio; WMD, weighted mean difference.

the infantile colic population; further research is needed to understand the prescribing practice in this field and the impact on the infants. Conversely, UK NICE guidance development group for the diagnosis and management of GORD stated that: "it was not unreasonable to offer a trial of either an $H_{2} R A$ or a PPI for suspected reflux oesophagitis in infants without endoscopic evidence and that the clinical presentation of reflux oesophagitis would usually be obvious" (NICE 2015).

Interestingly, the guidance and the evidence do not reflect each other; this may be due to the timing of published evidence and guideline development. The lack of consistent guidance available for parents, pharmacists and clinicians compounds the uncertainty relating to the care of infants with the symptoms of colic. ${ }^{49}$

We did not find any evidence around cost-effectiveness analyses of the treatments and there was not enough data to analyse our other outcomes of interest, sleep and parental distress.

\section{Strengths, limitations and challenges}

This review was limited to assessing four treatments. The two treatments, probiotics and manual therapy, indicated an effect on reducing crying time. We do not know, however, whether this reduction is meaningful to parents or whether it is sufficient to improve the 
Table 7 Summary of meta-analyses of treatments for infant colic measured by number of crying episodes

\begin{tabular}{|c|c|c|c|c|c|c|}
\hline Author & Intervention & Time point & Number of crying episodes & Effect & $\begin{array}{l}\text { Level of } \\
\text { evidence }\end{array}$ & AMSTAR \\
\hline Gordon et $a l^{18}$ & Simethicone & 14 days & $\begin{array}{l}3.32 \text { more episodes of crying and } \\
\text { fussing with simethicone compared } \\
\text { with partially hydrolysed formula }\end{array}$ & $\begin{array}{l}\text { Not favourable c/w } \\
\text { partially hydrolysed } \\
\text { formula }\end{array}$ & Very low & 8 \\
\hline Mugambi et $\left.a\right|^{25}$ & Probiotics & Up to 7 months & $\begin{array}{l}\text { MD } 0.60(95 \% \mathrm{Cl} 0.20 \text { to } 1.00) \text { in } \\
\text { favour of control for } 1 \text { out of } 4 \text { studies } \\
\text { reported }\end{array}$ & Not favourable & Low & 8 \\
\hline
\end{tabular}

MD, mean difference.

parent/infant relationship and/or the well-being of the infants, their parents and siblings. We did not compare manual therapy against other therapies such as dietary modification, herbal remedies, white noise, winding, swaddling and baby massage as suggested in some of the guidance. These other remedies and approaches do not appear to have a strong evidence base but are perhaps deemed to be relatively risk free by the expert consensus guidance panels. Although one recent editorial suggests that herbal mixtures and swaddling, while potentially effective, may be harmful because herbal mixtures may affect optimal milk consumption and swaddling may increase hip dysplasia. ${ }^{9}$ Simethicone and proton pump inhibitors were not considered as risk free and were not recommended in the guidance either explicitly or implicitly.

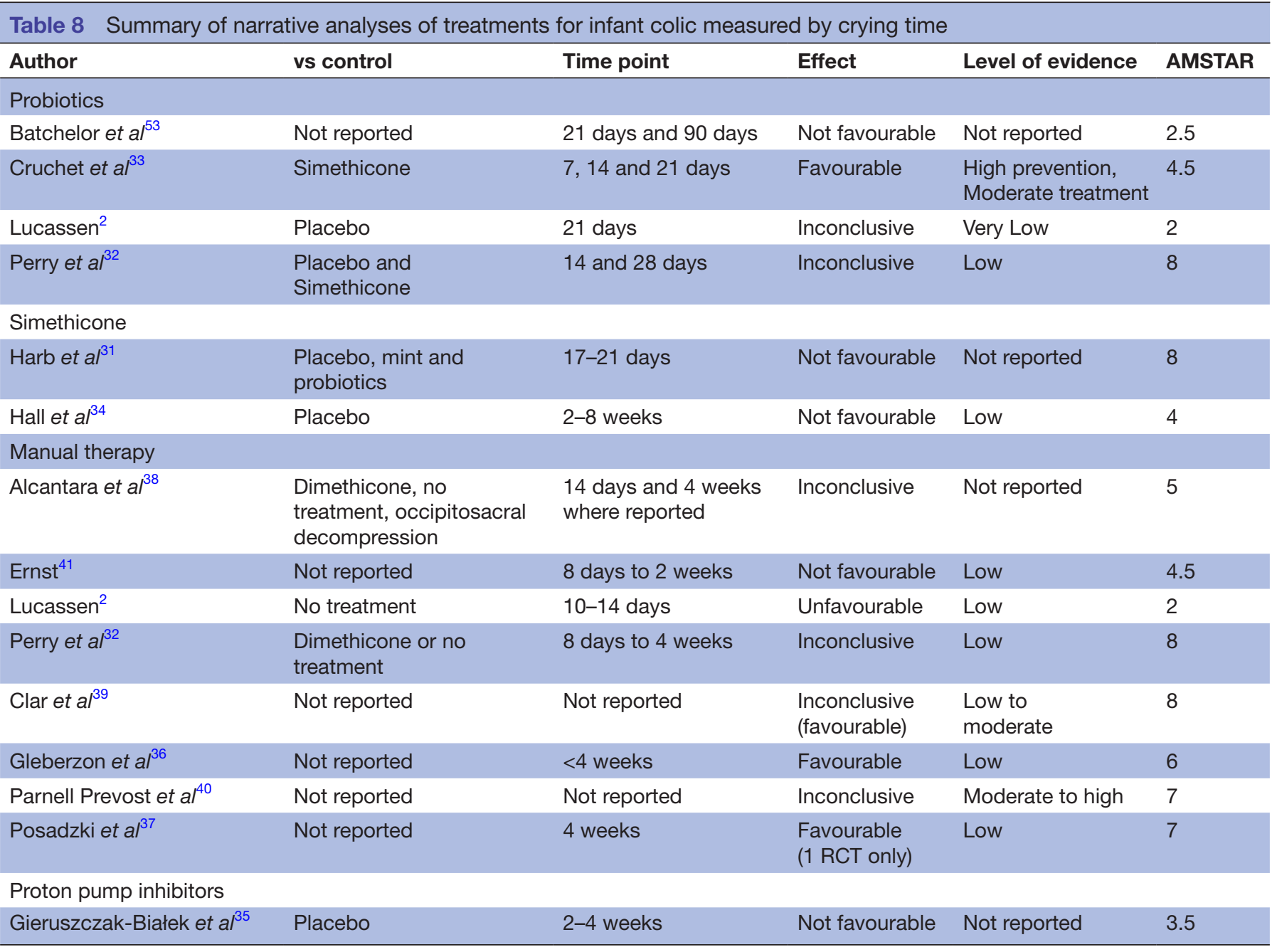

$\mathrm{RCT}$, randomised controlled trial. 
Table 9 National guideline recommendations infantile colic

\begin{tabular}{llll}
\hline Recommendation/suggestion & UK 2013 & USA & Ireland \\
\hline $\begin{array}{l}\text { Clinician evaluation of mother and } \\
\text { baby }\end{array}$ & $\checkmark$ & $\checkmark$ & $\checkmark$ \\
$\begin{array}{l}\text { Parenting information, advice, } \\
\text { support and reassurance }\end{array}$ & $\checkmark$ & $\checkmark$ & $\checkmark$ \\
$\begin{array}{l}\text { Continue breast feeding } \\
\text { Maternal diet modification }\end{array}$ & $\checkmark$ & $\checkmark$ & \\
$\begin{array}{l}\text { Change formula if formula fed } \\
\text { (+unless milk allergy identified) }\end{array}$ & $\times+$ & $\checkmark$ & \\
$\begin{array}{l}\text { Probiotic supplements } \\
\text { (++breastfed-only infants) }\end{array}$ & $\times$ & $\checkmark++$ & $\checkmark$ \\
$\begin{array}{l}\text { Simethicone (eg, infacol) } \\
\text { Herbal supplements (eg, fennel) }\end{array}$ & $\times$ & $\times$ \\
$\begin{array}{l}\text { Proton pump inhibitors (eg, } \\
\text { omeprazole, Losec) }\end{array}$ & & $\times$ \\
\hline
\end{tabular}

Lactase (eg, Co-lief drops) $\quad \times$

$\begin{aligned} & \text { Anitcholinergic medication } \\ & \text { (including dicyclomine) }\end{aligned} \times$

Gripe water $\quad \times$

Medicine generally

Infant massage

\begin{tabular}{l}
$\begin{array}{l}\text { Manual therapy (including } \\
\text { spinal manipulation and cranial } \\
\text { osteopathy) }\end{array}$ \\
$\begin{array}{l}\text { Physical contact (eg, holding, } \\
\text { rocking) }\end{array}$ \\
$\begin{array}{l}\text { White noise } \\
\text { Bathing }\end{array}$ \\
$\begin{array}{l}\text { Winding } \\
\text { Swaddling }\end{array}$ \\
$\begin{array}{l}\text { Acupuncture } \\
\text { Sleep routine }\end{array}$ \\
\hline
\end{tabular}

Blank boxes indicate no recommendation or suggestion made not considered or reported. Ticks indicate recommended interventions; cross indicates non-recommended interventions. *UK NICE www.nice.org.uk Clinical Knowledge Summary Infant Colic 2017 and Postnatal care: routine postnatal care of women and their babies (NICE Guideline, 2015).

†USA 2015 American Academy of Family Physicians (http:// www.aafp.org).

łlreland: Irish College of General Practitioners (https://www. icgp.ie).

In addition, it was not always clear what manual treatments were given and how many; therefore, we are unable to comment on type or quantity of manual treatment that may or may not have an effect.

We reviewed data published in the last decade to avoid over-duplication and we only reviewed articles published in English in peer-reviewed journals; this may have introduced some publication bias.
We suspect that the number and diversity of treatments that exist for infantile colic are borne out of desperation and lack of understanding about the aetiology of the colic and its persistence, although self-limiting in most cases. It has also been suggested that this has led to heterogeneous outcomes being measured, ${ }^{11}$ but several reviews were able to meta-analyse reduction in crying time. None of the reviews measured the well-being or confidence of the parents in managing their infants, or relationships and bonding between the parents and the infants and/or their siblings.

The strength of this review is that we have compared at least two treatments-probiotics and manual therapyfor colic and compared the recommendations in the guidance with the evidence which highlighted the difference in certainty between the evidence and the recommendations. This review found favourable but low to moderate quality evidence for manual therapy. This is different to other reviews, which generally reject manual therapy as an option due to poor quality data. New studies have raised the quality level of data and our more favourable interpretation may, in part, be due to the background of the authors and their understanding that manual therapy is a multicomponent therapy consisting of more than touch alone. The role of the manual therapist to reassure, guide, advise and support parents through this particularly difficult time may also have a therapeutic role to play which may affect parenting and outcomes. More high-quality studies are needed to increase the level of certainty surrounding the findings about the effect of manual therapy for infantile colic.

Future studies should consider the effect of treatment on the parents to explore parenting confidence, parent/ infant bonding and meaningful levels of change in crying and sleeping time.

Further research will probably change recommendations in the guidance as the evidence evolves and increases in quality. The guidance we reviewed did not reflect the emerging evidence. Overall, there is uncertainty about the management and care of infants with infantile colic in part due to the lack of consensus surrounding its aetiology and justification for treatments, although increasingly, newer research is providing plausible mechanistic explanations why probiotics may be beneficial due to the presence of gut inflammatory markers. ${ }^{50} 51$ Infantile colic is self-limiting in nature and understanding what symptoms and the level of reduction of these symptoms that are important to the infants and their carers needs further investigating. It is understandable that a range of approaches to treatment, management and care exist. Preserving parent choice and balancing this with the limited evidence about effectiveness and safety remains difficult to determine.

\section{CONCLUSIONS}

We found that the strongest evidence for the treatment of infantile colic was probiotics, particularly Lactobacillus reuteri for breastfed infants, followed by weaker but 
favourable evidence for manual therapy indicated by crying time. Both forms of treatment carried a low risk of serious adverse events. Current guidelines will probably change over time in light of existing new and emerging evidence.

Contributors DC conceptualised and designed the study, contributed to the data selection, extraction and analysis, drafted the initial manuscript, reviewed and revised the manuscript. JE managed the data, contributed to the data selection, extraction and analysis, reviewed and revised the manuscript. JD-R contributed to the data selection, extraction and analysis, reviewed and revised the manuscript. All the authors approved the final manuscript as submitted and agree to be accountable for all aspects of the work.

Funding This review was funded primarily by the Australian College of Chiropractic Paediatrics (ACCP) with part of the funding provided by the College of Chiropractic Paediatrics (CCP).

Disclaimer ACCP and CCP were not involved in the literature search, extraction of data, analysis and synthesis.

Competing interests None declared.

Patient consent for publication Not required.

Provenance and peer review Not commissioned; externally peer reviewed.

Data availability statement Full datasets, analyses and full searches are available on request from the corresponding author (Dawn.Carnes@uco.ac.uk). No individual patient-level data were used in this study.

Open access This is an open access article distributed in accordance with the Creative Commons Attribution Non Commercial (CC BY-NC 4.0) license, which permits others to distribute, remix, adapt, build upon this work non-commercially, and license their derivative works on different terms, provided the original work is properly cited, appropriate credit is given, any changes made indicated, and the use is non-commercial. See: http://creativecommons.org/licenses/by-nc/4.0/.

\section{ORCID iD}

Dawn Carnes http://orcid.org/0000-0002-3152-3133

\section{REFERENCES}

1 Lucassen PL, Assendelft WJ. Systematic review of treatments for infant colic. Pediatrics 2001;108:1047-8.

2 Lucassen P. Colic in infants. BMJ Clin Evid 2015;2015. [Epub ahead of print: 11 Aug 2015].

3 Wolke D, Bilgin A, Samara M. Systematic review and meta-analysis: fussing and crying durations and prevalence of colic in infants. $J$ Pediatr 2017;185:55-61.

4 Heine RG. Gastroesophageal reflux disease, colic and constipation in infants with food allergy. Curr Opin Allergy Clin Immunol 2006;6:220-5.

5 Steutel NF, Benninga MA, Langendam MW, et al. Reporting outcome measures in trials of infant colic. J Pediatr Gastroenterol Nutr 2014;59:341-6.

6 Wessel MA, Cobb JC, Jackson EB, et al. Paroxysmal fussing in infancy, sometimes called colic. Pediatrics 1954;14:421-35.

7 Zeevenhooven J, Browne PD, L'Hoir MP, et al. Infant colic: mechanisms and management. Nat Rev Gastroenterol Hepatol 2018;15:479-96.

8 Benninga MA, Faure C, Hyman PE, et al. Childhood functional gastrointestinal disorders: neonate/toddler. Gastroenterology 2016:1455.

9 Sung V. Infantile colic. Aust Prescr 2018;41:105-10.

10 Halpern R, Coelho R. Excessive crying in infants. J Pediatr 2016;92:S40-5.

11 Steutel NF, Benninga MA, Langendam MW, et al. Developing a core outcome set for infant colic for primary, secondary and tertiary care settings: a prospective study. BMJ Open 2017;7:e015418.

12 Johnson JD, Cocker K, Chang E. Infantile colic: recognition and treatment. Am Fam Physician 2015;92:577-82.

13 Kurth E, Spichiger E, Cignacco E, et al. Predictors of crying problems in the early postpartum period. J Obstet Gynecol Neonatal Nurs 2010;39:250-62.

14 Howard CR, Lanphear N, Lanphear BP, et al. Parental responses to infant crying and colic: the effect on breastfeeding duration. Breastfeed Med 2006;1:146-55.
15 Overpeck MD, Brenner RA, Trumble AC, et al. Risk factors for infant homicide in the United States. N Engl J Med 1998;339:1211-6.

16 Dobson D, Lucassen PLBJ, Miller JJ, et al. Manipulative therapies for infantile colic. Cochrane Database Syst Rev 2012;12:CD004796.

17 Ong TG, Gordon M, Banks SS, et al. Probiotics to prevent infantile colic. Cochrane Database Syst Rev 2019;3:CD012473.

18 Gordon M, Biagioli E, Sorrenti M, et al. Dietary modifications for infantile colic. Cochrane Database Syst Rev 2018;10:CD011029.

19 Biagioli E, Tarasco V, Lingua C, et al. Pain-relieving agents for infantile colic. Cochrane Database Syst Rev 2016;9:CD009999.

20 Liberati A, Altman DG, Tetzlaff J, et al. The PRISMA statement for reporting systematic reviews and meta-analyses of studies that evaluate healthcare interventions: explanation and elaboration. BMJ 2009;339:b2700.

21 Safe M, Chan WH, Leach ST, et al. Widespread use of gastric acid inhibitors in infants: are they needed? Are they safe? World $\mathrm{J}$ Gastrointest Pharmacol Ther 2016;7:531-9.

22 Garrison MM, Christakis DA. A systematic review of treatments for infant colic. Pediatrics 2000;106:184-90.

23 Shea BJ, Reeves BC, Wells G, et al. AMSTAR 2: a critical appraisal tool for systematic reviews that include randomised or nonrandomised studies of healthcare interventions, or both. BMJ 2017;358:j4008.

24 Brouwers MC, Kho ME, Browman GP, et al. AGREE II: advancing guideline development, reporting, and evaluation in health care. Prev Med 2010;51:421-4.

25 Mugambi MN, Musekiwa A, Lombard M, et al. Synbiotics, probiotics or prebiotics in infant formula for full term infants: a systematic review. Nutr J 2012;11:81.

26 Skórka A, Pieścik-Lech M, Kołodziej M, et al. To add or not to add probiotics to infant formulae? An updated systematic review. Benef Microbes 2017;8:717-25.

27 Posadzki P, Ernst E. Spinal manipulation: an update of a systematic review of systematic reviews. N Z Med J 2011;124:55-71.

28 Salehi A, Hashemi N, Imanieh MH, et al. Chiropractic: is it efficient in treatment of diseases? Review of systematic reviews. Int J Community Based Nurs Midwifery 2015;3:244-54.

29 Salvatore S, Barberi S, Borrelli O, et al. Pharmacological interventions on early functional gastrointestinal disorders. Ital J Pediatr 2016;42:68.

30 Gutiérrez-Castrellón P, Indrio F, Bolio-Galvis A, et al. Efficacy of Lactobacillus reuteri DSM 17938 for infantile colic: systematic review with network meta-analysis. Medicine 2017;96:e9375.

31 Harb T, Matsuyama M, David M, et al. Infant colic-what works: a systematic review of interventions for breast-fed infants. $J$ Pediatr Gastroenterol Nutr 2016;62:668-86.

32 Perry R, Hunt K, Ernst E. Nutritional supplements and other complementary medicines for infantile colic: a systematic review. Pediatrics 2011;127:720-33.

33 Cruchet S, Furnes R, Maruy A, et al. The use of probiotics in pediatric gastroenterology: a review of the literature and recommendations by Latin-American experts. Paediatr Drugs 2015;17:199-216.

34 Hall B, Chesters J, Robinson A. Infantile colic: a systematic review of medical and conventional therapies. J Paediatr Child Health 2012;48:128-37

35 Gieruszczak-Białek D, Konarska Z, Skórka A, et al. No effect of proton pump inhibitors on crying and irritability in infants: systematic review of randomized controlled trials. J Pediatr 2015;166:767-70.

36 Gleberzon BJ, Arts J, Mei A, et al. The use of spinal manipulative therapy for pediatric health conditions: a systematic review of the literature. J Can Chiropr Assoc 2012:56:128-41.

37 Posadzki P, Lee MS, Ernst E. Osteopathic manipulative treatment for pediatric conditions: a systematic review. Pediatrics 2013;132:140-52.

38 Alcantara J, Alcantara JD, Alcantara J. The chiropractic care of infants with colic: a systematic review of the literature. Explore 2011;7:168-74.

39 Clar C, Tsertsvadze A, Court R, et al. Clinical effectiveness of manual therapy for the management of musculoskeletal and nonmusculoskeletal conditions: systematic review and update of UK evidence report. Chiropr Man Therap 2014;22:12.

40 Parnell Prevost C, Gleberzon B, Carleo B, et al. Manual therapy for the pediatric population: a systematic review. BMC Complement Altern Med 2019;19:60.

41 Ernst E. Chiropractic spinal manipulation for infant colic: a systematic review of randomised clinical trials. Int J Clin Pract 2009;63:1351-3.

42 Driehuis F, Hoogeboom TJ, Nijhuis-van der Sanden MWG, et al. Spinal manual therapy in infants, children and adolescents: a systematic review and meta-analysis on treatment indication, technique and outcomes. PLoS One 2019;14:e0218940. 
43 Carnes D, Plunkett A, Ellwood J, et al. Manual therapy for unsettled, distressed and excessively crying infants: a systematic review and meta-analyses. BMJ Open 2018;8:e019040.

44 Blank M-L, Parkin L. National study of off-label proton pump inhibitor use among New Zealand infants in the first year of life (2005-2012). J Pediatr Gastroenterol Nutr 2017;65:179-84.

45 Duncan DR, Mitchell PD, Larson K, et al. Association of proton pump inhibitors with hospitalization risk in children with oropharyngeal dysphagia. JAMA Otolaryngol Head Neck Surg 2018;144:1116-24.

46 Mitre E, Susi A, Kropp LE, et al. Association between use of AcidSuppressive medications and antibiotics during infancy and allergic diseases in early childhood. JAMA Pediatr 2018;172:e180315.

47 Bell JC, Schneuer FJ, Harrison C, et al. Acid suppressants for managing gastro-oesophageal reflux and gastro-oesophageal reflux disease in infants: a national survey. Arch Dis Child 2018;103:archdischild-2017-314161.

48 Marchand V. Using probiotics in the paediatric population. Paediatr Child Health 2012;17:575-6.

49 Hinds R, Loveridge N, Lemberg DA, et al. Functional gastrointestinal disorders in infants: practice, knowledge and needs of Australian pharmacists. J Paediatr Child Health 2019. doi:10.1111/jpc.14536. [Epub ahead of print: 10 Jun 2019].

50 Rhoads JM, Collins J, Fatheree NY, et al. Infant colic represents gut inflammation and dysbiosis. J Pediatr 2018;203:55-61.

51 Pärtty A, Kalliomäki M, Salminen S, et al. Infantile colic is associated with low-grade systemic inflammation. J Pediatr Gastroenterol Nutr 2017;64:691-5.
52 Anabrees J, Indrio F, Paes B, et al. Probiotics for infantile colic: a systematic review. BMC Pediatr 2013;13:186.

53 Batchelor N, Kelly J, Choi H, et al. Towards evidence-based emergency medicine: best BETs from the Manchester Royal Infirmary. BET 2: probiotics and crying time in babies with infantile colic. Emerg Med J 2015;32:575-6.

54 Dryl R, Szajewska H. Probiotics for management of infantile colic: a systematic review of randomized controlled trials. Arch Med Sci 2018;14:1137-43.

55 Schreck Bird A, Gregory PJ, Jalloh MA, et al. Probiotics for the treatment of infantile colic: a systematic review. J Pharm Pract 2017;30:366-74.

56 Sung V, Collett S, de Gooyer T, et al. Probiotics to prevent or treat excessive infant crying: systematic review and meta-analysis. JAMA Pediatr 2013:167:1150-7.

57 Sung V, D'Amico F, Cabana MD, et al. Lactobacillus reuteri to treat infant colic: a meta-analysis. Pediatrics 2018;141:e20171811.

58 Xu M, Wang J, Wang N, et al. The efficacy and safety of the probiotic bacterium Lactobacillus reuteri DSM 17938 for infantile colic: a meta-analysis of randomized controlled trials. PLoS One 2015;10:e0141445

59 Urbańska M, Szajewska $H$. The efficacy of Lactobacillus reuteri DSM 17938 in infants and children: a review of the current evidence. Eur $J$ Pediatr 2014;173:1327-37. 